\title{
EFFECTS OF FIRE AND HERBIVORY ON THE STABILITY OF SAVANNA ECOSYSTEMS
}

\author{
Frank van Langevelde,${ }^{1,10}$ Claudius A. D. M. Van de Vijver,${ }^{1,2}$ Lalit Kumar, ${ }^{1,3}$ Johan van de \\ Koppel,,${ }^{1,4}$ Nico de Ridder, ${ }^{5}$ Jelte van Andel, ${ }^{6}$ Andrew K. Skidmore, ${ }^{3}$ John W. Hearne, ${ }^{7}$ \\ Leo Stroosnijder,${ }^{8}$ William J. Bond,${ }^{2}$ Herbert H. T. Prins,${ }^{1}$ And Max Rietkerk ${ }^{9}$

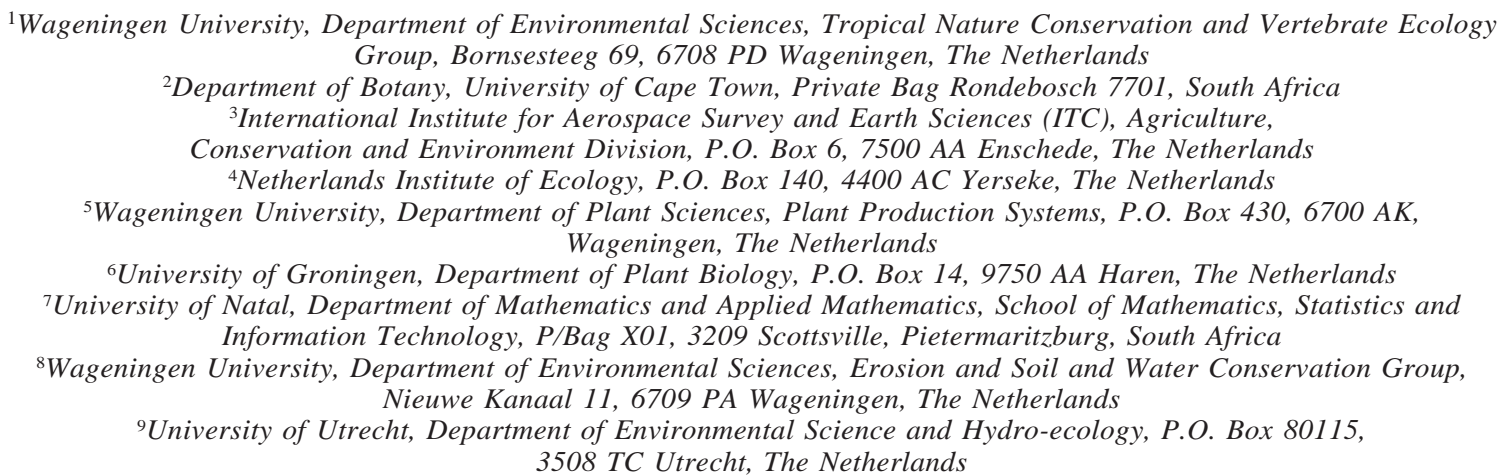

Abstract. Savanna ecosystems are characterized by the co-occurrence of trees and grasses. In this paper, we argue that the balance between trees and grasses is, to a large extent, determined by the indirect interactive effects of herbivory and fire. These effects are based on the positive feedback between fuel load (grass biomass) and fire intensity. An increase in the level of grazing leads to reduced fuel load, which makes fire less intense and, thus, less damaging to trees and, consequently, results in an increase in woody vegetation. The system then switches from a state with trees and grasses to a state with solely trees. Similarly, browsers may enhance the effect of fire on trees because they reduce woody biomass, thus indirectly stimulating grass growth. This consequent increase in fuel load results in more intense fire and increased decline of biomass. The system then switches from a state with solely trees to a state with trees and grasses. We maintain that the interaction between fire and herbivory provides a mechanistic explanation for observed discontinuous changes in woody and grass biomass. This is an alternative for the soil degradation mechanism, in which there is a positive feedback between the amount of grass biomass and the amount of water that infiltrates into the soil. The soil degradation mechanism predicts no discontinuous changes, such as bush encroachment, on sandy soils. Such changes, however, are frequently observed. Therefore, the interactive effects of fire and herbivory provide a more plausible explanation for the occurrence of discontinuous changes in savanna ecosystems.

Key words: alternate stable states; browsing; bush encroachment; fire; grazing; herbivory; positive feedback; savanna; stability; tree-grass balance.

\section{INTRODUCTION}

Semiarid savanna ecosystems are characterized by a continuous grass layer intermixed with a discontinuous layer of trees and shrubs. The co-occurrence of trees (including shrubs) and grasses is determined by a complex set of interacting factors (Bond and Van Wilgen 1996, Scholes and Archer 1997). Soil moisture availability is one of the main abiotic factors that determines the growth of trees and grasses in these systems. Trees and grasses compete for this resource, which is primarily determined by rainfall, physical soil character-

Manuscript received 27 July 2001; revised 8 March 2002; accepted 22 April 2002; final version received 17 June 2002 Corresponding Editor: W. K. Lauenroth.

${ }^{10}$ E-mail: frank.vanlangevelde@wur.nl istics, and landscape position (Scholes and Archer 1997 and references therein). However, apart from variations in these abiotic conditions, other factors also influence woody and grass biomass changes in both time and space.

Several studies have attributed spatial (Jeltsch et al. 1996, 1998) and temporal (Higgins et al. 2000) variations in woody and grass biomass to drought, fire, and herbivores, which affect opportunities for recruitment and establishment of trees. An example of temporal variation is demonstrated by the consequences of the rinderpest pandemic in East Africa at the end of the 19th century. This pandemic decimated livestock and wildlife populations, causing famine and starvation in the human population and, consequently, a large decline in anthropogenic fires and herbivory (Dublin et 


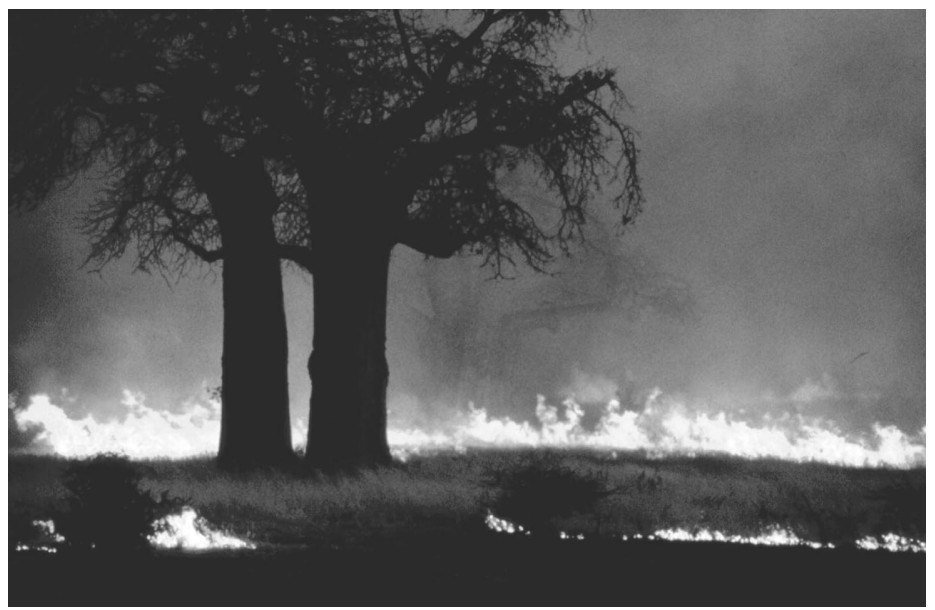

Plate 1. Savanna fire. Photograph by Claudius van de Vijver.

al. 1990). This coincided with a strong increase in the cover of woody species. Recovery of both human numbers in subsequent years, and thus the return of anthropogenic fires (see Plate 1) and herbivore numbers, was associated with a decline of woody biomass (Sinclair 1979).

In the past 20-30 yr, a similar trend of bush encroachment is occurring in many savanna areas. This time, however, it is ascribed to overgrazing by livestock and changes in fire regime in combination with years of drought (Walker et al. 1981, Barnes 1983, Scholes and Walker 1993, Scholes and Archer 1997).

These examples demonstrate discontinuous changes in savanna ecosystems: through certain events, a specific state of the vegetation is replaced by another, a change that can be irreversible. These alternate vegetation states have been identified by various authors, who have shown that the concept of alternate stable states is relevant to understanding savanna ecosystem dynamics (Noy-Meir 1975, Walker et al. 1981, Dublin et al. 1990, Perrings and Walker 1997, Rietkerk and Van de Koppel 1997). Moreover, these examples show the decisive role of fire and herbivory, as well as the variation in their effects.

Fire and herbivory affect savannas through both direct and indirect effects. Intense fires cause a direct decline in the cover of woody vegetation by killing trees or by reducing trees to smaller size classes. Likewise, browsing herbivores reduce woody vegetation, such that trees are either killed or reduced in size (Stuart-Hill and Tainton 1989, Prins and Van der Jeugd 1993), the effect of elephants being most profound and well known (Dublin et al. 1990, Dublin 1995). The combined effect of fire and herbivory led to the hypothesis that fire causes the decline in woody vegetation whereas browsers inhibit recovery (Dublin et al. 1990, Belsky 1995, Scholes and Archer 1997). However, there is also a profound indirect effect of fire and herbivory on the tree-grass balance.
Grass biomass removal through grazing leads to reduced fuel load, which makes fire less intense and, thus, less damaging to trees; consequently, it may result in an increase in woody vegetation (Trollope 1984, Sav-
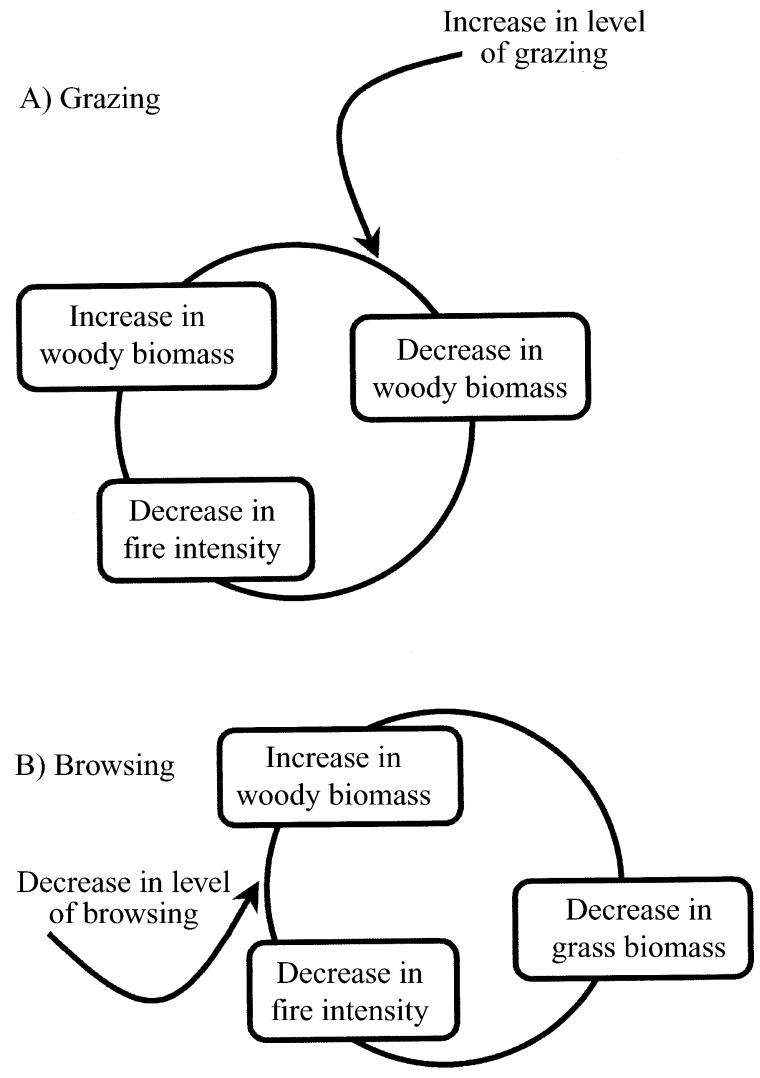

FIG. 1. Positive feedback mechanism between grass biomass (fuel load) and fire intensity, triggered by (A) grazing and (B) browsing. A decrease in grass biomass leads to reduced fuel load that makes fire less intense and, thus, less damaging to trees, consequently resulting in an increase in woody vegetation. 
FIG. 2. Peak standing grass biomass (mean and $95 \% \mathrm{CI} ; n=5$ ) in burned and unburned vegetation during a dry year $(350 \mathrm{~mm}$ rainfall) and a wet year $(940 \mathrm{~mm})$, measured on four different soil types in Tarangire National Park, Tanzania (Van de Vijver 1999). The vegetation was burned at the beginning of the rainy season.

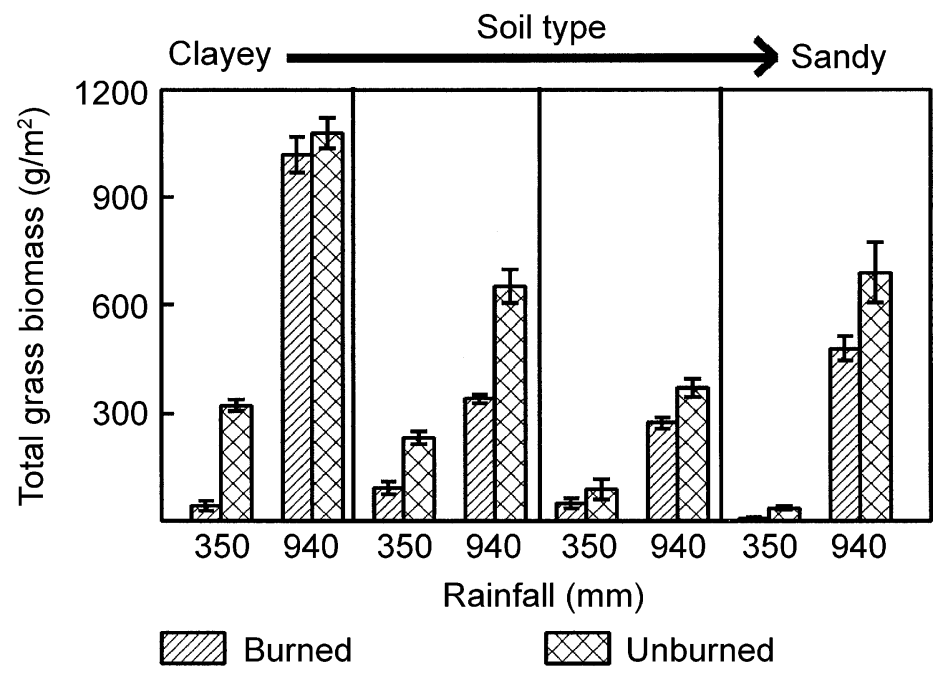

age and Swetnam 1990, Kaufmann et al. 1994). On the other hand, browsers may enhance the effect of fire on trees because they reduce the woody biomass, which accordingly promotes grass growth. The consequent increase in fuel load results in more intense fire, thus decreasing woody biomass. Although the importance of the indirect, interactive effects of fire, grazing, and browsing on savanna dynamics has been generally accepted (Norton-Griffiths 1979, Walker 1993, Belsky 1995, Scholes and Archer 1997, Van de Vijver 1999, Higgins et al. 2000), the actual consequences for the tree-grass balance have hardly been investigated.

In this paper, we address this issue by analyzing a simple model that investigates the interactive effects of fire, grazing, and browsing on the tree-grass balance in savannas, depending on soil type and soil moisture availability. We provide insight into the existence of alternate vegetation states and discontinuous changes of these states under different levels of grazing, browsing, and fire frequency.

\section{A Model of Tree-Grass Dynamics}

We describe the savanna dynamics by the changes in the grass and woody biomass, where grass biomass consists of both grasses and herbs, and woody biomass consists of wood, twigs, and leaves of trees and shrubs. Because larger trees are hardly affected by fire and herbivory, we consider only the smaller trees and shrubs up to $5 \mathrm{~m}$, as these often contribute most of the biomass in savanna ecosystems (Van de Vijver et al. 1999). The balance between grasses and trees shifts when grazing, browsing, and fire intensity change. The relationship between fire intensity and the growth of trees and grasses, as mediated by either grazing or browsing, is shown in Fig. 1. This figure indicates that a reduction in fire intensity and, hence, in damage to trees can be the result of either increased grazing (Fig. 1A) or an indirect result of decreased browsing (Fig. 1B).
The rate of change of grass biomass depends on the available soil moisture, mortality, consumption rate of the grazers, and the impact of fire on grass biomass. Grasses and trees compete for the available soil moisture, and we assume niche separation in the rooting zone of grasses and trees (Walter 1971). According to the two-layer assumption, grasses are the superior competitors in the topsoil layer, where both grasses and trees root (Jackson et al. 1996). In this paper, the topsoil layer is referred to as the grass root zone. Although some grasses have access to water in deeper soil layers, called the tree root zone, the contribution of this water to their survival can be considered negligible, because very few grass roots penetrate to these depths (Pratt and Gwynne 1977, Knoop and Walker 1985, Weltzin and McPherson 1997, Schenk and Jackson 2002). Because we discuss the tree-grass interactions at the landscape level, we therefore neglect the possible uptake of moisture by grasses from the tree root zone. The part of the model describing the competition for water between trees and grasses and the niche separation is essentially the same as that used by Walker et al. (1981) and Walker and Noy-Meir (1982).

Fire negatively affects the total grass biomass, including dead and litter material (Van de Vijver 1999; see Fig. 2). We assume that the impact of fire on the total grass biomass, in subsequent years after a fire, is linearly related to the fire frequency; a higher frequency will reduce the build-up of total biomass over time. Grass survival is rarely affected by fire (Van de Vijver 1999), so we assume no negative effects of fire on grass growth.

In the model, the proportion of water uptake per unit grass biomass from the grass root zone is defined as follows (Walker et al. 1981):

$$
U_{H}=\frac{\theta_{H}}{\theta_{H} H+\theta_{W} W+w_{\mathrm{s}}}
$$

where $\theta_{H}$ and $\theta_{W}$ are the rates of water uptake per unit 
TABLE 1. List of the parameters and variables used, their interpretation, units, estimated values, and literature sources.

\begin{tabular}{|c|c|c|c|c|}
\hline $\begin{array}{l}\text { Parameters } \\
\text { and } \\
\text { variables }\end{array}$ & Interpretation & Units & Values & Sources \\
\hline$H$ & grass biomass & $\mathrm{g} / \mathrm{m}^{2}$ & $0-400$ & $\begin{array}{l}\text { Kelly and Walker (1976), Walker et } \\
\text { al. (1981), Van de Vijver (1999) }\end{array}$ \\
\hline$W$ & woody biomass & $\mathrm{g} / \mathrm{m}^{2}$ & $0-1000$ & $\begin{array}{l}\text { Kelly and Walker (1976), Le Houér- } \\
\text { ou (1980), Walker et al. (1981) }\end{array}$ \\
\hline$r_{H}$ & water use efficiency of grasses & $\mathrm{g} / \mathrm{mm}$ & 1.0 & Gambiza et al. (2000) \\
\hline$r_{W}$ & water use efficiency of trees & $\mathrm{g} / \mathrm{mm}$ & 0.5 & $\begin{array}{l}\text { Kelly and Walker (1976), Bille } \\
\text { (1980), Lamprey et al. (1980) }\end{array}$ \\
\hline$U_{H}$ & $\begin{array}{l}\text { proportion of water uptake per } \\
\text { unit grass biomass }\end{array}$ & $\mathrm{m}^{2} / \mathrm{g}$ & See Eq. 1 & Walker et al. (1981) \\
\hline$U_{W}$ & $\begin{array}{l}\text { proportion of water uptake per } \\
\text { unit woody biomass }\end{array}$ & $\mathrm{m}^{2} / \mathrm{g}$ & See Eq. 3 & Walker et al. (1981) \\
\hline$\theta_{H}$ & $\begin{array}{l}\text { rate of water uptake per unit } \\
\text { grass biomass }\end{array}$ & $\mathrm{mm} \cdot \mathrm{yr}^{-1} \cdot \mathrm{g}^{-1}$ & 0.9 & Walker et al. (1981) \\
\hline$\theta_{W}$ & $\begin{array}{l}\text { rate of water uptake per unit } \\
\text { woody biomass }\end{array}$ & $\mathrm{mm} \cdot \mathrm{yr}^{-1} \cdot \mathrm{g}^{-1}$ & 0.5 & Walker et al. (1981) \\
\hline$u$ & $\begin{array}{l}\text { ratio of the rate of uptake of wa- } \\
\text { ter by trees to that by grasses }\end{array}$ & & 0.6 & Walker et al. (1981) \\
\hline$w_{\text {in }}$ & $\begin{array}{l}\text { annual amount of infiltrated wa- } \\
\text { ter }\end{array}$ & $\mathrm{mm} \cdot \mathrm{m}^{-2} \cdot \mathrm{yr}^{-1}$ & $0-1000$ & \\
\hline$w_{\mathrm{t}}$ & $\begin{array}{l}\text { rate of moisture recharge in the } \\
\text { grass root zone }\end{array}$ & $\mathrm{mm} \cdot \mathrm{m}^{-2} \cdot \mathrm{yr}^{-1}$ & See Eq. 4 & \\
\hline$w_{\mathrm{s}}$ & $\begin{array}{l}\text { rate of moisture recharge in the } \\
\text { tree root zone }\end{array}$ & $\mathrm{mm} \cdot \mathrm{m}^{-2} \cdot \mathrm{yr}^{-1}$ & See Eq. 5 & \\
\hline$d_{H}$ & $\begin{array}{l}\text { specific loss of grass biomass } \\
\text { due to mortality }\end{array}$ & $\mathrm{yr}^{-1}$ & 0.9 & Gambiza et al. (2000) \\
\hline$d_{W}$ & $\begin{array}{l}\text { specific loss of woody biomass } \\
\text { due to mortality }\end{array}$ & $\mathrm{yr}^{-1}$ & 0.4 & $\begin{array}{l}\text { Le Houérou (1980) and references } \\
\text { within }\end{array}$ \\
\hline$c_{H}$ & $\begin{array}{l}\text { consumption coefficient of grass } \\
\text { biomass by grazers }\end{array}$ & $\mathrm{m}^{2} \cdot \mathrm{g}^{-1} \cdot \mathrm{yr}^{-1}$ & 0.02 & $\begin{array}{l}\text { Van Soest (1982), Van Wieren } \\
\text { (1992) }\end{array}$ \\
\hline$c_{W}$ & $\begin{array}{l}\text { consumption coefficient of } \\
\text { woody biomass by browsers }\end{array}$ & $\mathrm{m}^{2} \cdot \mathrm{g}^{-1} \mathrm{yr}^{-1}$ & 0.02 & $\begin{array}{l}\text { Van Soest (1982), Van Wieren } \\
\text { (1992) }\end{array}$ \\
\hline$G$ & grazer biomass & $\mathrm{g} / \mathrm{m}^{2}$ & $0-30$ & \\
\hline$B$ & browser biomass & $\mathrm{g} / \mathrm{m}^{2}$ & $0-15$ & \\
\hline$k_{H}$ & $\begin{array}{l}\text { specific loss of grass biomass } \\
\text { due to fire }\end{array}$ & $\mathrm{yr}^{-1}$ & 0.1 & Van de Vijver (1999) \\
\hline$k_{W}$ & $\begin{array}{l}\text { specific loss of woody biomass } \\
\text { due to a fire expressed per } \\
\text { unit energy }\end{array}$ & $\mathrm{W}^{-1}$ & 0.01 & $\begin{array}{l}\text { Trollope (1984), Trollope and Trol- } \\
\text { lope (1996), Higgins et al. (2000) }\end{array}$ \\
\hline$n$ & frequency of fires per year & $\mathrm{yr}^{-1}$ & $0-1$ & \\
\hline$a$ & $\begin{array}{l}\text { coefficient for the increase in } \\
\text { fire intensity with grass bio- } \\
\text { mass }\end{array}$ & $\mathrm{W} \cdot \mathrm{m}^{-2} \cdot \mathrm{g}^{-1}$ & 0.5 & $\begin{array}{l}\text { Trollope (1998), Higgins et al. } \\
\text { (2000) }\end{array}$ \\
\hline$\alpha$ & $\begin{array}{l}\text { proportion of excess water that } \\
\text { percolates }\end{array}$ & & 0.4 & De Ridder and Van Keulen (1995) \\
\hline$\beta$ & $\begin{array}{l}\text { soil moisture content in the grass } \\
\text { root zone above which water } \\
\text { starts to percolate to the tree } \\
\text { root zone }\end{array}$ & $\mathrm{mm} \cdot \mathrm{m}^{-2} \mathrm{yr}^{-1}$ & $200-500$ & De Ridder and Van Keulen (1995) \\
\hline
\end{tabular}

biomass of grasses and trees, respectively; $H$ is the grass biomass; $W$ is the woody biomass; and $w_{\mathrm{s}}$ is the loss of water in the grass root zone through percolation to the tree root zone. The utilization of water from the grass root zone by grass is given by $U_{H} H$, expressed as a proportion of the total amount of water available in the grass root zone (Walker and Noy-Meir 1982). Eq. 1 can be rearranged as

$$
U_{H}=\frac{1}{H+u W+p w_{\mathrm{s}}}
$$

where $u$ is the ratio of the rate of uptake of water by trees to that by grasses $\left(\theta_{W} / \theta_{H}\right) ; p=1 / \theta_{H}$.
The rate of change of grass biomass $H$ over one year can then be represented by the differential equation

$$
\begin{aligned}
\frac{d H}{d t}= & r_{H} w_{\mathrm{t}} \frac{H}{H+u W+p w_{\mathrm{s}}}-d_{H} H-c_{H} G H \\
& -k_{H} n H
\end{aligned}
$$

where $r_{H}$ is the water use efficiency of the grasses and $w_{\mathrm{t}}$ is the rate of recharge of moisture in the grass root zone. The parameter $d_{H}$ is the specific loss of grass biomass due to mortality; $c_{H}$ is the consumption coefficient of grass biomass by grazers, with $G$ as the biomass of the grazers. The parameter $k_{H}$ is the specific loss of grass biomass due to fire, and $n$ is the frequency 
FIG. 3. Effect of fire intensity on stem mortality of shrubs in the arid savannas of the Eastern Cape (EC) and the Kruger National Park (KNP) in South Africa (Trollope 1996). In the EC, the most common shrub species, Acacia karroo, is more resistant to fire when it is above $\sim 2 \mathrm{~m}$ in height, whereas in KNP, this threshold height is $\sim 3.5 \mathrm{~m}$.

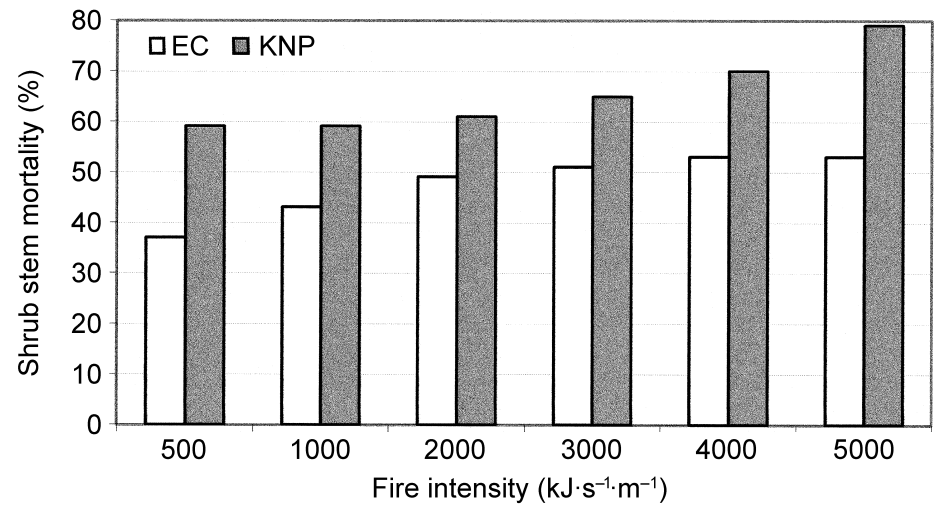

of fires per year, given that $0 \leq n \leq 1$. In Table 1 , the symbols, their interpretation, units, and estimated values are enumerated. These parameter values were based on literature and expert judgment.

In the model, we assume that water that infiltrates on a yearly basis is available for the growth of grasses and trees. This water increases the soil moisture content in the grass root zone up to a certain threshold. Although the grass root zone is not yet saturated, water starts to percolate to the tree root zone beyond this threshold. We assume that under arid and semiarid conditions, both grass and tree root zones are not saturated. For reasons of simplicity, we also assume that all infiltrated water is directly available for grass and tree growth: there is no wilting point beyond which they cannot survive. The rate of recharge of moisture in the grass root zone is thus

$$
w_{\mathrm{t}}=w_{\text {in }}-w_{\mathrm{s}}
$$

where $w_{\text {in }}$ is the amount of infiltrated water per year. The parameter $w_{\mathrm{s}}$ is proportional to the amount of infiltrated water:

$$
w_{\mathrm{s}}=\alpha\left(w_{\text {in }}-\beta\right) \quad \text { if } w_{\text {in }}>\beta, \quad \text { or else } w_{\mathrm{s}}=0
$$

where $\beta$ is the soil moisture content in the grass root zone above which water starts to percolate to the tree root zone, and $\alpha$ is the proportion of excess water above the soil moisture content $\beta$ that percolates to the tree root zone. Because we have time steps of $1 \mathrm{yr}$, the proportion of excess water $\alpha$ is based on the number of times the moisture content in the grass root zone exceeds the soil moisture content $\beta$ due to rainfall. $\beta$ depends on a variety, of factors, of which soil type is the prime determinant. It is much lower in coarse-textured, sandy soils than in fine-textured, clayey soils (Dingman 1994, De Ridder and Van Keulen 1995). Although $\beta$ depends on soil type, $\alpha$ is kept constant (De Ridder and Van Keulen 1995).

Woody biomass depends on the amount of soil moisture available for trees in the grass root zone and tree root zone, mortality, consumption by the browsers, and loss through fire. Fire intensity is linearly related to the amount of grass biomass (Trollope 1998, Higgins et al.
2000), and the impact of fire on the woody biomass is also linearly related to the fire intensity. Trollope and coworkers (Trollope 1984, 1996, 1998, Trollope and Trollope 1996) empirically investigated these relationships. They developed a statistical model using 200 monitored fires in South African savannas, showing that, in addition to vegetation moisture content, relative humidity, and wind speed, the realized fire intensity is primarily determined by grass biomass, the driving fuel for savanna fires (see Higgins et al. 2000). The relationship between fire intensity and tree damage was investigated using data on the effects of fire intensity on stem mortality in two savannas in South Africa. In both areas, Higgins et al. (2000) found greater stem mortality with increasing fire intensity (Fig. 3); they developed a statistical model to predict stem mortality using the survival rates of trees. Based on data on the survival rate of 7400 stems of 76 tree species in 40 fires of known intensities, they demonstrated that an increase in fire intensity leads to higher stem mortality.

Like the water uptake for the grasses, the proportion of water uptake per unit woody biomass from the grass root zone is

$$
U_{W}=\frac{\theta_{W}}{\theta_{H} H+\theta_{W} W+w_{\mathrm{s}}}=\frac{u}{H+u W+p w_{\mathrm{s}}} .
$$

The rate of change of total aboveground woody biomass $W$ over one year can therefore be represented by the differential equation

$$
\begin{aligned}
\frac{d W}{d t}= & r_{W}\left[w_{\mathrm{t}} \frac{u W}{H+u W+p w_{\mathrm{s}}}+w_{\mathrm{s}}\right]-d_{W} W \\
& -c_{W} B W-k_{w} n a H W
\end{aligned}
$$

where $r_{W}$ is the water use efficiency of trees; $d_{W}$ is the specific loss of woody biomass due to mortality; $c_{W}$ is the consumption coefficient of woody biomass by browsers; and $B$ is the biomass of the browsers. The trees use water from both the grass root zone $\left(w_{\mathrm{t}}\right)$ and the tree root zone $\left(w_{\mathrm{s}}\right)$. The parameter $k_{W}$ is the specific loss of woody biomass due to a fire, expressed per unit energy; $a$ is the coefficient for the increase in fire intensity with grass biomass. 

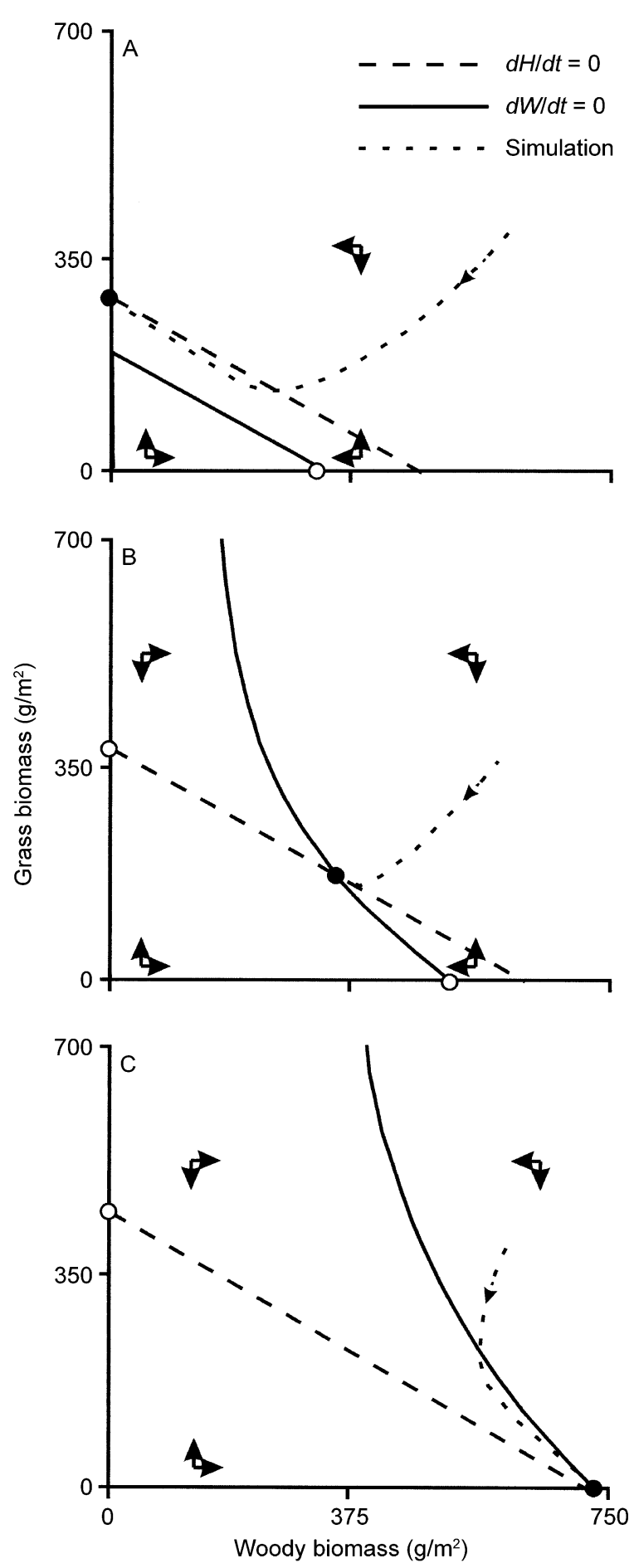

FIG. 4. The zero isoclines for woody biomass $(d W / d t=$ $0)$ and grass biomass $(d H / d t=0)$ drawn in a phase plane for different amounts of infiltrated water, excluding the effects of grazing, browsing, or fire $(G=B=n=0$, where $G$ and $B$ are grazer and browser biomass, respectively, and $n$ is fire frequency). The vectors indicate the direction of change. The dotted line illustrates the path that the system follows over time, given a certain starting point. Solid circles indicate a stable equilibrium, and open circles indicate an unstable equilibrium. (A) A small amount of infiltrated water, $w_{\text {in }}<\beta$ (Eqs.

\section{RESULTS}

Tree-grass balance without effects of grazing,
browsing, and fire

We first analyzed the model without the effects of grazing, browsing, and fire in order to obtain insight into how abiotic conditions (water availability and soil texture) affect vegetation structure. One way to analyze the dynamics of the tree-grass model is by plotting the zero isoclines of the woody and grass biomass in a phase plane (Fig. 4). The grass isocline is the line joining combinations of woody and grass biomass where grass biomass does not change $(d H / d t=0)$. With decreasing grass biomass, the woody biomass equilibrium increases linearly, independent of the amount of infiltrated water. The tree isocline is the line showing combinations of woody and grass biomass where the change in woody biomass is zero $(d W / d t=0)$. The two isoclines in the phase plane may result in several equilibria.

Grasses are able to suppress the woody vegetation when the amount of infiltrated water $\left(w_{\text {in }}\right)$ is below the soil moisture content above which water starts to percolate to the tree root zone $(\beta)$. In this situation, the tree isocline is located under the grass isocline (Fig. 4A). Two equilibria exist: the stable grassland equilibrium $\left(0, \bar{H}_{b}\right)$ where the grass isocline meets the $H$-axis, and the unstable woodland equilibrium $\left(\bar{W}_{b}, 0\right)$ where the tree isocline meets the $W$-axis. When the amount of infiltrated water increases (i.e., as a result of increased sandiness or rainfall), the tree isocline bends upward and shifts to the right, because more water percolates to the tree root zone that promotes the growth of the trees. Now, the trees and grasses cooccur. In the phase plane, three equilibria can be found: the two unstable boundary equilibria $\left(\bar{W}_{b}, 0\right)$ with no grasses and $\left(0, \bar{H}_{b}\right)$ with no trees, and one stable internal equilibrium $(\bar{W}, \bar{H})$; see Fig. 4B. This internal equilibrium occurs until the tree isocline is located above the grass isocline, due to a further increase in the amount of infiltrated water (Fig. 4C). In this situation, one stable woodland equilibrium exists at $\left(\bar{W}_{b}, 0\right)$. Formal stability analyses of these equilibria are given in the Appendix.

$\leftarrow$

4 and 5), leads to one stable equilibrium $(0, \bar{H})$ with solely grasses and one unstable equilibrium $\left(\bar{W}_{b}, 0\right)$. (B) When the amount of infiltrated water increases so that $w_{\text {in }}>\beta$, the woody vegetation appears, and a stable equilibrium $(\bar{W}, \bar{H})$ with both grasses and trees can be found. Then, the boundary equilibria $(0, \bar{H})$ and $\left(\bar{W}_{b}, 0\right)$ are unstable. (C) A further increase in the amount of infiltrated water leads to the disappearance of grasses, and trees then dominate the vegetation. The boundary equilibrium $\left(\bar{W}_{b}, 0\right)$ is stable. Parameter values are: $r_{H}=1, r_{W}=0.5, p=1, d_{H}=0.9, d_{W}=0.4, u=0.6$, $\alpha=0.4, \beta=300$; (A) $w_{\text {in }}=250$; (B) $w_{\text {in }}=500$; (C) $w_{\text {in }}=$ 750. See Table 1 for definitions. 


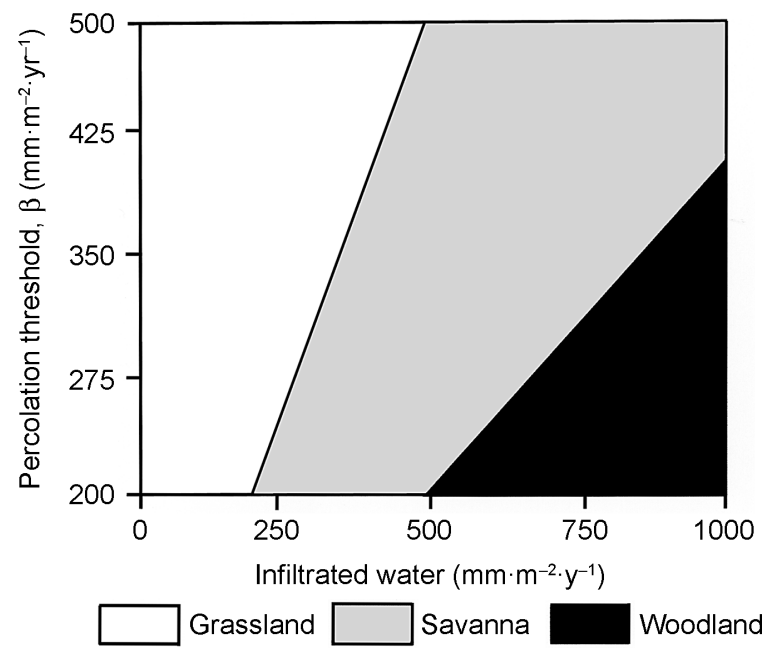

FIG. 5. Parameter plane of the amount of infiltrated water $\left(w_{\text {in }}\right)$ and the soil water content where water starts to percolate to the tree root zone $(\beta)$ showing the three vegetation states of grassland, savannas, and woodland (cf. Walker and NoyMeir 1982). Low values for $\beta$ represent sandy soils, and high values represent clayey soils. Changes in the parameter values change the stable states for woody and grass biomass. $\mathrm{Pa}$ rameter values are: $r_{H}=1, r_{W}=0.5, p=1, d_{H}=0.9, d_{W}=$ $0.4, k_{H}=0.1, k_{W}=0.01, u=0.6, \alpha=0.4$. See Table 1 for definitions.

This stability analysis shows that parameter variations affect the existence and stability properties of the tree and grass equilibria. Each time the qualitative behavior of an equilibrium changes, a so-called point of bifurcation is reached (e.g., Edelstein-Keshet 1988). In a parameter plane, we can investigate the effects of parameter changes on the shape and position of the bifurcation sets. In Fig. 5, the effects of the amount of infiltrated water $\left(w_{\text {in }}\right)$ and the soil moisture content $\beta$ on the tree-grass balance are shown, without the effects of herbivory and fire. Based on these two abiotic factors, the occurrence of various vegetation structures of semiarid systems can be explained. With the increase in water availability, the vegetation shows transitions from grassland to savanna with both trees and grasses (where water starts to percolate) and from savanna to woodland (where the growth rate of the woody biomass exceeds that of grass biomass). This agrees with the expectations for the vegetation structure as discussed by Walker and Noy-Meir (1982), who also attribute the grassland to savanna to woodland gradient to rainfall and soil texture.

Fig. 5 shows that on sandy soils (low value for $\beta$ ) trees can occur for a lower range of infiltrated water than on clayey soils. Observations support this: trees establish under drier conditions on sandy soils than on clayey soils (Pratt and Gwynne 1977, Walker et al. 1981, Scholes and Archer 1997).

\section{Effects of grazing, browsing, and fire on the tree-grass balance}

With fire and herbivory in the model, two, three, or even four equilibria can exist in the phase plane (Fig.
6). The interactive effects of herbivory and fire become important when woodland dominates, or, in terms of the phase plane, when the tree isocline is located above the grass isocline and the equilibrium $\left(\bar{W}_{b}, 0\right)$ is stable

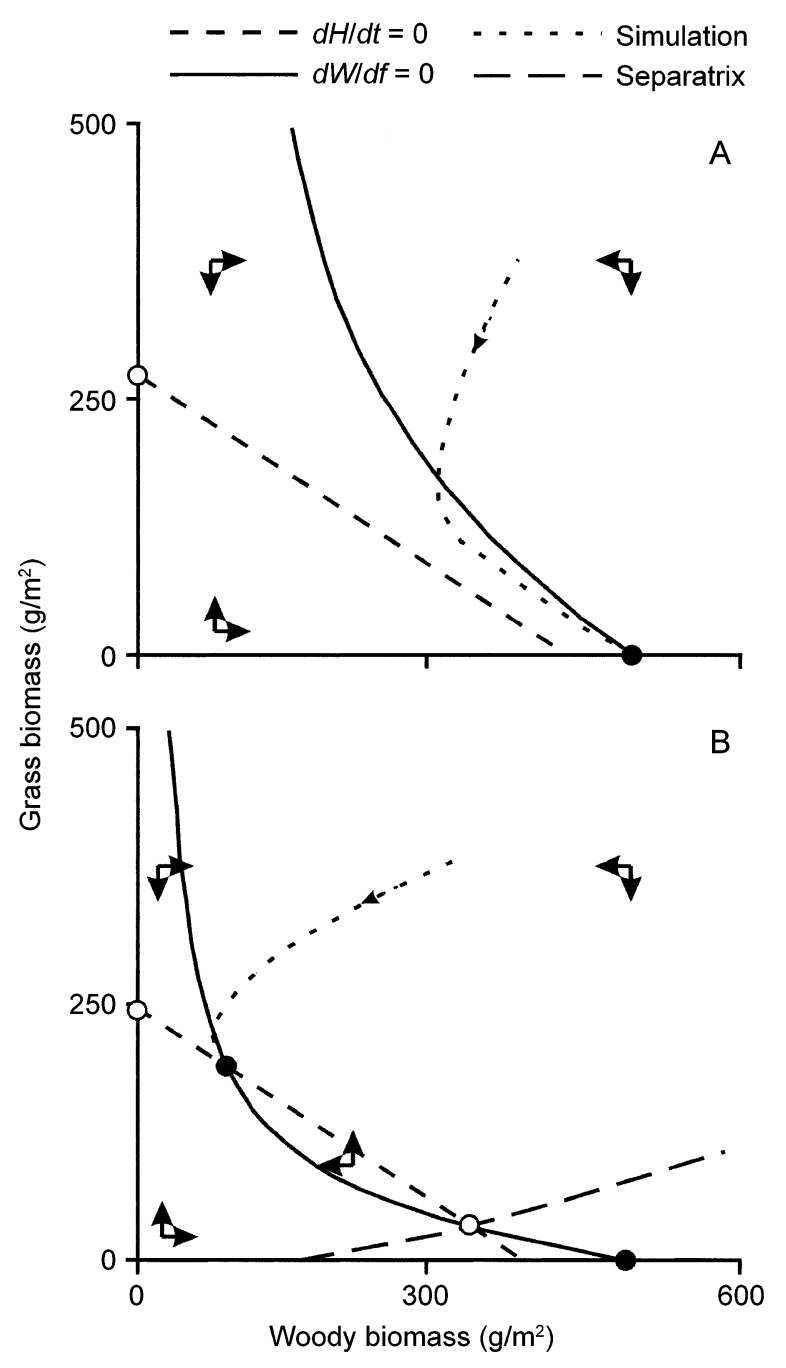

FIG. 6. The zero isoclines for woody biomass $(d W / d t=$ $0)$ and grass biomass $(d H / d t=0)$ drawn in a phase plane for fixed values of the amount of infiltrated water $\left(w_{\text {in }}\right)$ and the soil water content at which water starts to percolate to the tree root zone $(\beta)$, but different fire frequencies, including effects of grazing and browsing. The vectors indicate the direction of change. The dotted line illustrates the path that the system follows during time, given a certain starting point. Solid circles indicate a stable equilibrium, and open circles indicate an unstable equilibrium. (A) Low fire frequency and a high amount of infiltrated water result in woody dominance, where the boundary equilibrium $\left(\bar{W}_{b}, 0\right)$ is stable and the boundary equilibrium $(0, \bar{H})$ is unstable (compare with Fig. 4C). (B) High fire frequency leads to two stable internal equilibria at $\left(\bar{W}_{1}, \bar{H}_{1}\right)$ and $\left(\bar{W}_{b}, 0\right)$, and two unstable equilibria at $(0, \bar{H})$ and $\left(\bar{W}_{2}, \bar{H}_{2}\right)$. Parameter values are: $r_{H}=1, r_{W}=0.5$, $p=1, d_{H}=0.9, d_{W}=0.4, k_{H}=0.1, k_{W}=0.01, u=0.6, \alpha$ $=0.4, \beta=300, w_{\text {in }}=700, c_{H}=c_{W}=0.02, a=0.5, B=$ $5, G=15$. In panel (A), $n=0.1$; in panel (B), $n=0.9$. See Table 1 for definitions. 

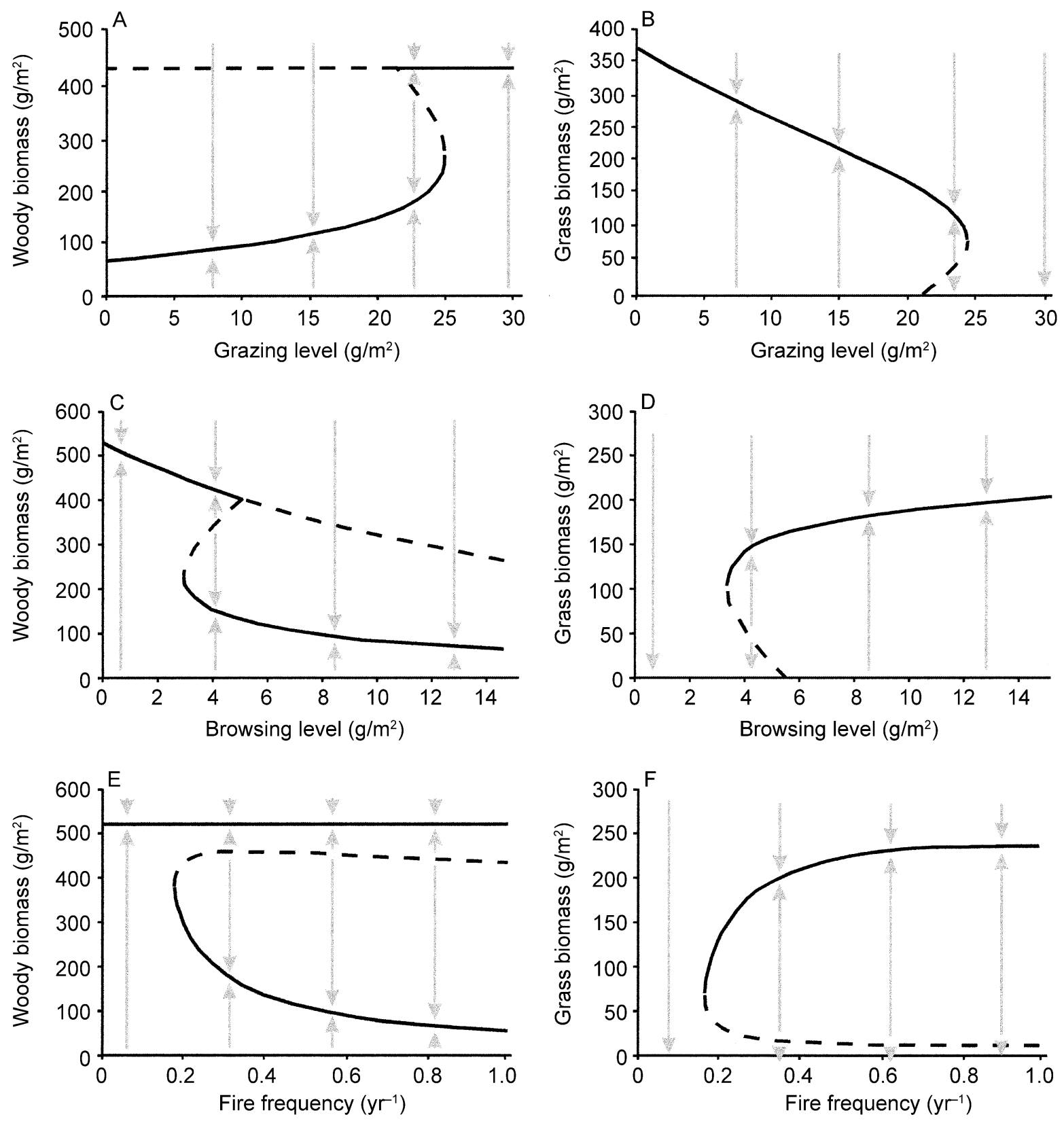

FIG. 7. Changes in the equilibrium woody and grass biomass with levels of grazing and browsing and fire frequency. Sudden jumps of woody and grass biomass occur at distinct levels of grazing, browsing, and fire frequency. Solid lines give the stable equilibria, and dashed lines give the unstable equilibria. Arrows indicate the direction of development. Parameter values (see Table 1) are: $r_{H}=1, r_{W}=0.5, p=1, d_{H}=0.9, d_{W}=0.4, k_{H}=0.1, k_{W}=0.01, u=0.6, \alpha=0.4, \beta=300, w_{\text {in }}$ $=500, c_{H}=c_{W}=0.02, a=0.5$. For (A) and (B), $B=5, n=0.2$; for (C) and (D), $G=25, n=0.2$; for (E) and (F), $B=$ $5, G=15$.

(Fig. 6A). The shift from savanna toward woodland can be induced by an increase in the amount of infiltrated water (as in Fig. 4C) or in grazing level (decrease of the grass biomass), or by a decrease in browsing level (increase of the woody biomass).

We set the amount of infiltrated water at a constant level where woodland dominates while fire frequency may vary. Under the conditions of a low fire frequency, only woodland occurs (Fig. 6A). The equilibrium ( $\bar{W}_{b}$, 0 ) is then stable. An increase in fire frequency leads to the existence of alternate stable states: both savanna vegetation and woodland can exist under these conditions (Fig. 6B). Four equilibria are found: a stable equilibrium without grasses $\left(\bar{W}_{b}, 0\right)$, one stable internal equilibrium with both grasses and trees $\left(\bar{W}_{1}, \bar{H}_{1}\right)$, and two unstable equilibria $\left(\bar{W}_{2}, \bar{H}_{2}\right)$ and $\left(0, \bar{H}_{b}\right)$. Analysis 
of the phase plane also shows that there is a threshold in fire frequency. When the frequency is below this threshold, fire causes less damage to the trees and woodland is able to dominate, whereas both grasses and trees can exist above this threshold. The two domains with different attracting equilibria that occur in the phase plane are separated by a separatrix, representing this threshold (dashed line). For initial values of the grass and woody biomass under the separatrix, the system shifts to the equilibrium $\left(\bar{W}_{b}, 0\right)$; otherwise, it develops toward $\left(\bar{W}_{1}, \bar{H}_{1}\right)$.

Both internal and boundary equilibria of the system are shown in Fig. 7 as function of the level of grazing, browsing, and fire frequency. The solid lines give the stable equilibria for woody and grass biomass, whereas the dashed lines refer to the unstable equilibria. This figure shows that discontinuous changes in grass and woody biomass occur at distinct levels of grazing, browsing, or fire frequency when these increase or decrease. This discontinuous property may produce hysteresis (Lockwood and Lockwood 1993, Rietkerk et al. 1996). Discontinuous changes in the vegetation structure due to changes in the level of grazing or browsing and fire frequency may be irreversible to a certain extent. For example, events such as droughts may carry the grass biomass below a break point value (indicated by the separatrix) allowing bush encroachment to occur. Note that such shifts can occur through small changes in grass biomass. A decrease in the level of grazing, however, will only stimulate the recovery of grass biomass when it is reduced to a lower level than the level where the collapse occurred. In terms of Fig. 7 , the level of grazing should be reduced to the level where the curved dashed line intersects the line indicating the maximum woody biomass.

The existence of alternate stable states depends critically on the relationship between fuel load (grass biomass) and fire intensity, i.e., the coefficient for the increase in fire intensity with grass biomass: $a$ in Eq. 7 . When we apply a weaker relationship between grass biomass and fire intensity, a lower value of $a$, the parameter range with alternate stable states becomes smaller and will disappear. The latter means that there are also no hysteresis effects with changing levels of grazing or browsing and fire frequency, as in Fig. 7.

In Fig. 8, the effects of the amount of infiltrated water $\left(w_{\text {in }}\right)$ and the percolation threshold $(\beta)$ on the tree-grass balance are shown (as in Fig. 5), including the effect of fire, grazing, and browsing. These diagrams show under what conditions grassland, savanna, or woodland can be found. They also give the parameter space where alternate stable states can be expected: either savanna vegetation or woodland. Because of an increase in fire frequency, the range for which alternate stable states are predicted increases at the expense of the woodland range. At the same time, the increase in browsing intensity increases the parameter range where savanna vegetation can be found, whereas an increase in grazing leads to an increase in the woodland range at the expense of the savanna range. For the conditions where alternate stable states are predicted, discontinuous changes such as bush encroachment can occur when there are small changes in either grass or woody biomass.

\section{DISCUSSION}

This study shows that the interactive effects of fire and herbivory have a large impact on the woody and grass biomass in savanna ecosystems. These effects critically hinge on the positive feedback between fuel load (grass biomass) and fire intensity. Changes in the level of both grazing and browsing may trigger this positive feedback, in which a change in grass biomass results in a change in fuel load. An increase in grass biomass leads to more intense fires and more damage to trees, consequently allowing grass biomass to increase. On the other hand, a decrease in grass biomass, and thus fire intensity, may lead to bush encroachment. When fire intensity strongly increases with fuel load, alternate stable states of savanna vegetation and woodland exist under certain conditions. The vegetation is then vulnerable for discontinuous changes from savanna vegetation to woodland.

The interaction between fire and herbivory is an alternative for the soil degradation mechanism (Walker et al. 1981, Walker and Noy-Meir 1982) in explaining alternate vegetation states of savanna and woodland and discontinuous changes of these states. This soil degradation mechanism is based on the positive feedback between grass biomass and water infiltration: increasing infiltration with increasing grass biomass (Kelly and Walker 1976, Walker et al. 1981, Walker and Noy-Meir 1982, Rietkerk et al. 1997, Rietkerk and Van de Koppel 1997). It is modeled as

$$
w_{\text {in }}=\frac{H+c_{1} i_{0}}{H+c_{1}}
$$

where $w_{\text {in }}$ is the amount of water that infiltrates; $H$ is the grass biomass; $c_{1}$ is the rate at which infiltration increases with $H$; and $i_{0}$ is the infiltration in the absence of grass biomass. On sandy soils, there is a high water infiltration in the absence of plants, whereas there is low water infiltration in the absence of plants on clayey soils due to soil degradation, e.g., crust formation (Kelly and Walker 1976, Rietkerk et al. 1997). The model with this infiltration function predicts the existence of alternate stable states on clayey soils, whereas they are not predicted on sandy soils. This is because overgrazing on clayey soils leads to a decrease in water infiltration in the grass root zone, which enhances woody biomass that uses an independent deep soil water source, whereas on sandy soils, overgrazing has little effect on infiltration.

However, field observations show that bush encroachment occurs on both sandy and clayey soils (Pratt and Gwynne 1977, Doudill et al. 1998). Our 


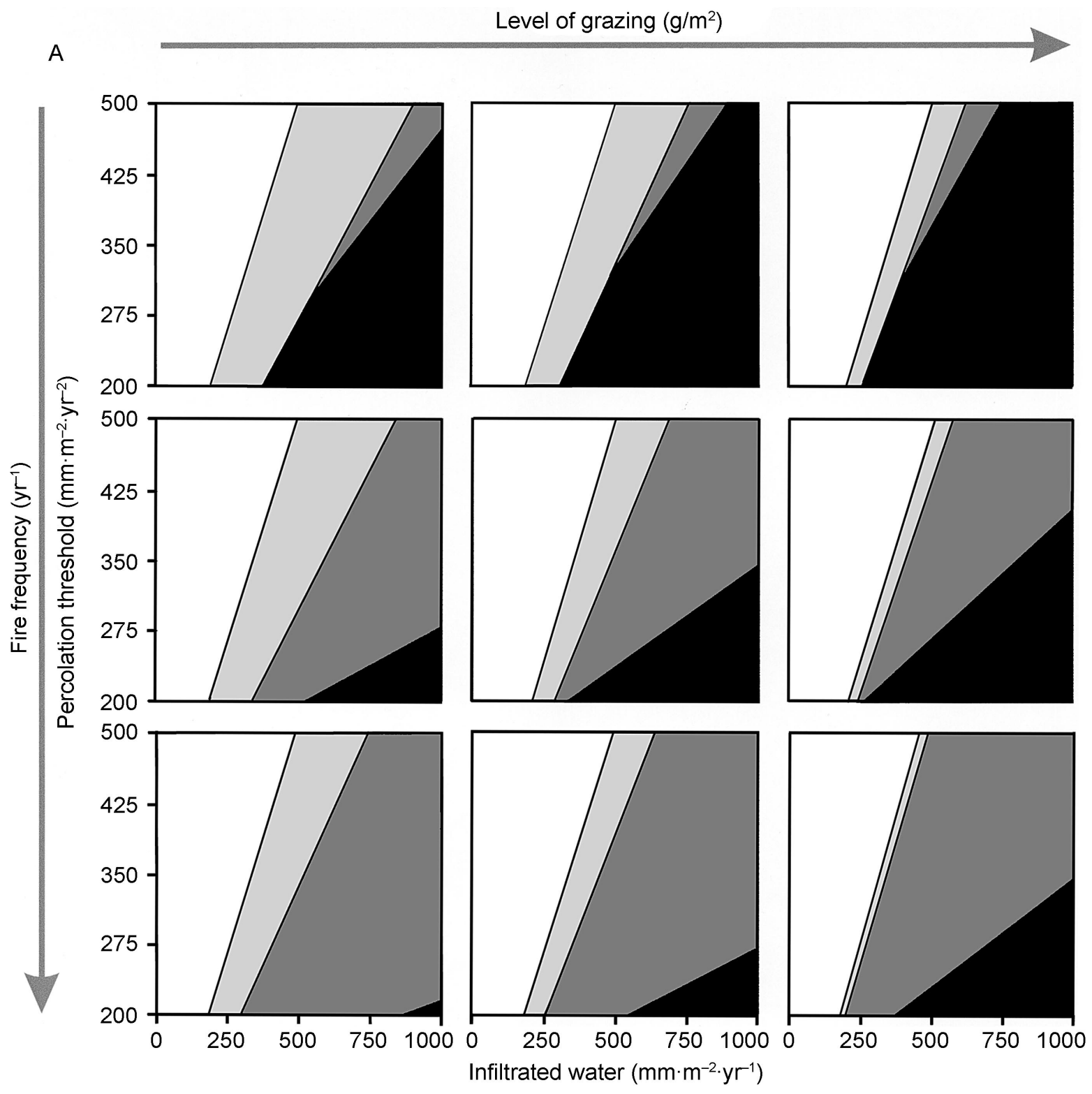

FIG. 8. Parameter plane of the amount of infiltrated water $\left(w_{\text {in }}\right)$ and the soil water content where water starts to percolate to the tree root zone $(\beta)$ for three vegetation states: grassland, savannas, and woodland. Low values for $\beta$ represent sandy soils, and high values represent clayey soils. Changes in the parameter values change the stable states for woody and grass biomass. Different zones in the parameter planes are related to the different stable states of grassland, savanna, and woodland, as is demonstrated in the phase planes of Figs. 4 and 6, Fig. 4A-C showing the stable state of grassland, savanna, and woodland, respectively, and Fig. 6B showing the alternate stable states of savanna and woodland. The parameter planes are given for different values of fire frequency, grazing, and browsing: from low to high fire frequency $(n=0.1,0.5$, and 1.0$)$, from low to high grazing pressure $(G=5,10$, and 15), and for a low (A) and high (B, facing page) browsing pressure (B $=0$ and 5). Parameter values (see Table 1) are: $r_{H}=1, r_{W}=0.5, p=1, d_{H}=0.9, d_{W}=0.4, k_{H}=0.1, k_{W}=0.01, u=0.6$, $\alpha=0.4, a=0.5, c_{H}=c_{W}=0.02$.

results predict that under certain levels of grazing, browsing, and fire frequency, discontinuous changes in the vegetation structure are possible on both clayey and sandy soils. Therefore, the interactive effects of fire and herbivory provide a more plausible explanation for the occurrence of discontinuous changes in savanna ecosystems.
Various field observations have shown that by reducing grazing intensities and increasing browsing intensities in areas that have become encroached by bush, the cover of woody species can be significantly reduced with fire as compared to situations in which grazing intensity is kept high (Lamprey et al. 1980, Trollope and Trollope 1996, Trollope 1998). Moreover, the pre- 


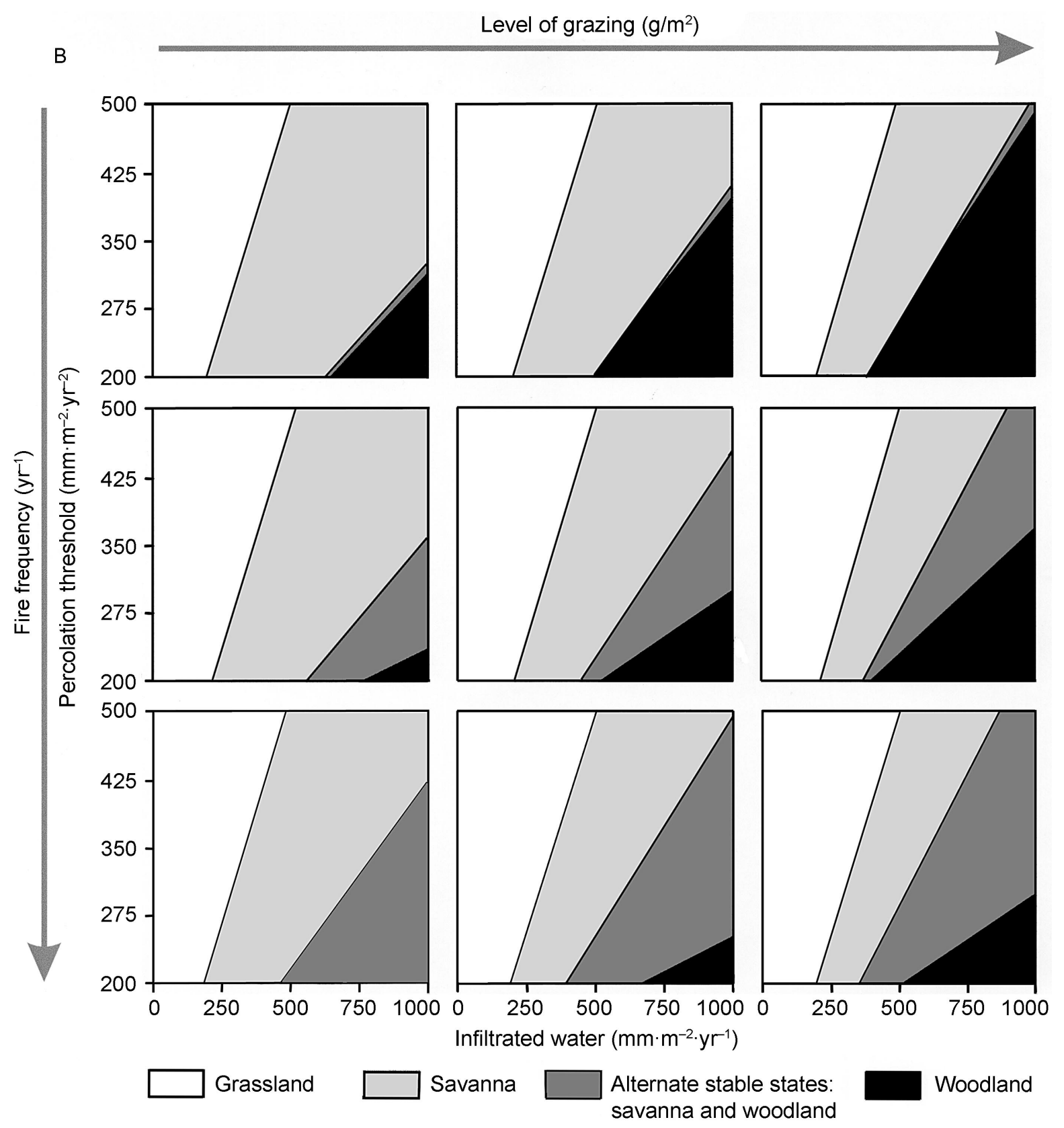

FIG. 8. Continued.

dictions for grass and woody biomass, based on specific parameter values for fire frequency, browser and grazer biomass, soil type, and rainfall, lie in the range of data from sparse field observations (Kelly and Walker 1976, Le Houérou 1980, Walker et al. 1981, Van de Vijver 1999).

Our model could, with certain parameter values, explain observed discontinuous changes in vegetation structure in time, such as during and after the rinderpest pandemic (Sinclair 1979), grassland expansion in the Serengeti-Mara (Dublin et al. 1990), and the current increase of woody cover observed in many savannas
(Scholes and Archer 1997). The rinderpest pandemic led to an increase in woody biomass as result of a drastic decline in the levels of grazing and browsing and fire frequency (compare Fig. 6A and B). The model could predict that the increase in woodland during the rinderpest and the decline afterward is primarily the result of changes in browsing and fire, rather than grazing. The model shows that, although a decline in grazing leads to more intense fire and an increase in the savanna range, the impacts of the decrease in browsing and fire frequency are larger because these result in a larger decrease in, respectively, the savanna range and 
the alternate stable state range (Fig. 8). These predictions support the hypothesis of Dublin et al. (1990), who first argued that the combined effects of browsing and fire are responsible for woodland decline and grassland expansion, as observed in the Serengeti-Mara.

At present, there is a strong increase in woody cover, i.e., the bush encroachment problem (Hudak 1999), due to an increased level of grazing that reduces the parameter range of savanna vegetation to the advantage of woodland (Fig. 8). An increase in fire frequency enlarges the parameter range with the alternate stable states. This may lead to an increase in savanna vegetation if a certain threshold is crossed (Fig. 6B). However, the savanna vegetation is then vulnerable to bush encroachment. This agrees with observations that an increase in fire frequency can cause bush encroachment (Pratt and Gwynne 1977, Gillon 1983, Smith 1992).

The relationship between fuel load and fire intensity depends on several factors, such as fuel moisture, relative humidity, and wind speed (Trollope 1998). These factors vary within and between seasons. Traditionally, anthropogenic fires occurred at the end of the dry season (Homewood and Rodgers 1991, Smith 1992). Nowadays, however, fires are also lit at the end of the wet season or beginning of the dry season to obtain nutritious postfire regrowth for grazing (McNaughton 1985). These changes in the timing of fires are assumed to promote bush encroachment (Van Vegten 1983, Archer 1996). We could explain this bush encroachment by less intense fire, given a certain amount of fuel load, because of higher fuel moisture and relative humidity at the end of the wet season and the beginning of the dry season. This would decrease the coefficient for the increase in fire intensity with grass biomass $(a)$, which would lead to the dominance of trees under the conditions in which the model predicts two stable states of savanna vegetation and woodland when there is a stronger relationship between fuel load and fire intensity.

When the amount of infiltrated water $\left(w_{\text {in }}\right)$ decreases, trees may die and woodland may become savanna. In the phase plane, the point where the tree isocline meets the $H$-axis, $\left(\bar{W}_{b}, 0\right)$, then shifts to a value below the grass isocline, as shown in Fig. 4B. This implies that a drought decreases the effects of bush encroachment. This has also been shown by Ludwig et al. (1997), who include wet and dry years in their model because trees may die back quickly in dry years, but recover slowly in wet years. However, although the moisture recharge rate in the tree root zone $\left(w_{\mathrm{s}}\right)$ drops during one year of drought, a decrease in the amount of available moisture will not immediately deplete the moisture content in the tree root zone, and thus the trees will remain. Apart from a long period of drought, only changes in the levels of grazing and browsing and fire regime may decrease the encroachment of woody species (Trollope 1984, 1998).
In the literature, several deterministic and stochastic models are presented that explain the tree-grass dynamics in savannas (e.g., Walker et al. 1981, Dublin et al. 1990, Hochberg et al. 1994, Jeltsch et al. 1996, 1998, Ludwig et al. 1997, Perrings and Walker 1997, Higgins et al. 2000). In the stochastic approaches, the coexistence of trees and grasses can be explained by spatial and temporal stochasticity (Jeltsch et al. 1996, 1998, Higgins et al. 2000). In this paper, we use a deterministic approach to model the tree-grass balance. Several authors state that savannas are not represented by a stable mixture of trees and grasses, but are an inherently unstable mixture that persists owing to events such as drought, fire, and herbivory (Scholes and Walker 1993, Jeltsch et al. 1996, 1998, Scholes and Archer 1997, Higgins et al. 2000). The discussion as to whether a deterministic approach is valid in savanna ecosystems is often coupled with the question as to whether the rooting niche separation assumption is valid (Jeltsch et al. 1996, 1998, Scholes and Archer 1997, Higgins et al. 2000). In the deterministic approaches, the rooting niche separation is the only mechanism thus far that can explain the coexistence of trees and grasses. It has been argued that there is evidence against this niche separation assumption because it appears that most roots of trees and grasses are in the upper soil layers (Scholes and Walker 1993, Belsky 1994). However, evidence for niche separation also exists (Knoop and Walker 1985, Sala et al. 1989, Weltzin and McPherson 1997), particularly in drier areas (Schenk and Jackson 2002). Moreover, the presence of hydraulic lift in trees suggests that the roots of these trees reach water sources that cannot be reached by the grasses (Caldwell et al. 1998).

As Scholes and Archer (1997:535) state, "no single model can account for the variety of phenomena at all savanna locations, or even the range of behaviors exhibited at one location in different seasons or stages of succession." In our model, we highlight the interactions between fire and herbivory, through grass fuel load, as being an important mechanism in explaining observed patterns. The fact that savanna systems are usually not at equilibrium, due to drought, for example, obscures the existence of such an underlying mechanism. However, this in itself is not evidence for the weakness of these interactions (cf. Illius and O'Connor 1999). Therefore, we have chosen a simple approach focusing on a specific mechanism to unravel the cause and effects of discontinuous dynamics. Regardless of the discussion about event-driven systems or the rooting niche separation assumption, this paper shows the importance of the interactive effects of fire and herbivory on the tree-grass balance in savannas.

\section{ACKNOWLEDGMENTS}

We would like to thank Steven Higgins, Gregory Kiker, Fulco Ludwig, Craig Morris, Tim O'Connor, Kyle Tomlinson, and Winston Trollope for their useful suggestions and comments on the manuscript. Winston Trollope is also thanked 
for supplying us with necessary data. This study was financially supported by the Netherlands Foundation for Tropical Research (WOTRO), residing under the Netherlands Organization for Scientific Research (NWO) (FLARE-programme "Fundamentals of African Rangeland Economies").

\section{Literature Cited}

Archer, S. R. 1996. Assessing and interpreting grass-woody plant dynamics. Pages 101-134 in J. Hodgson and A. W. Illius, editors. The ecology and management of grazing systems. CAB International, Wallingford, Oxon, UK.

Barnes, R. F. W. 1983. Effects of browsing on woodlands in a Tanzanian National Park: measurements, models, and management. Journal of Applied Ecology 20:521-540.

Belsky, A. J. 1994. Influences of trees on savanna productivity: tests of shade, nutrients, and tree-grass competition. Ecology 75:922-932.

Belsky, A. J. 1995. Spatial and temporal landscape patterns in arid and semi-arid African savannas. Pages 31-54 in L. Hansson, L. Fahrig, and G. Merriam, editors. Mosaic landscapes and ecological processes. Chapman and Hall, London, UK.

Bille, J. C. 1980. Measuring the primary palatable production of browse plants. Pages 185-196 in H. N. Le Houérou, editor. Browse in Africa: the current state of knowledge. International Livestock Centre for Africa, Addis Ababa, Ethiopia.

Bond, W. J., and B. W. Van Wilgen. 1996. Fire and plants. Chapman and Hall, London, UK.

Caldwell, M. M., T. E. Dawson, and J. H. Richards. 1998. Hydraulic lift: consequences of water efflux from the roots of plants. Oecologia 113:151-161.

De Ridder, N., and H. Van Keulen. 1995. Estimating biomass through transfer functions based on simulation model results: a case study for the Sahel. Agricultural Water Management 28:57-71.

Dingman, S. L. 1994. Physical hydrology. Prentice Hall, Englewood Cliffs, New Jersey, USA.

Doudill, A. J., A. L. Heathwaite, and D. S. G. Thomas. 1998. Soil water movement and nutrient cycling in semi-arid rangeland: vegetation change and system resilience. Hydrological Processes 12:443-459.

Dublin, H. T. 1995. Vegetation dynamics in the SerengetiMara ecosystem: the role of elephants, fire and other factors. Pages 71-90 in A. R. E. Sinclair and P. Arcese, editors. Serengeti II, Dynamics, management and conservation of an ecosystem. University of Chicago Press, Chicago, Illinois, USA.

Dublin, H. T., A. R. E. Sinclair, and J. McGlade. 1990. Elephants and fire as causes of multiple stable states in the Serengeti-Mara woodlands. Journal of Animal Ecology 59: $1147-1164$.

Edelstein-Keshet, L. 1988. Mathematical models in biology. McGraw-Hill, New York, New York, USA.

Gambiza, J., W. Bond, P. G. H. Frost, and S. Higgins. 2000. Land use options in dry tropical woodland ecosystems in Zimbabwe. Ecological Economics 33:353-368.

Gillon, D. 1983. The fire problem in tropical savannas. Pages 617-641 in F. Bourlière, editor. Tropical savannas. Elsevier, Amsterdam, The Netherlands.

Higgins, S. I., W. J. Bond, and W. S. W. Trollope. 2000. Fire, resprouting and variability: a recipe for grass-tree coexistence in savanna. Journal of Ecology 88:213-229.

Hochberg, M. E., J. C. Menaut, and J. Gignoux. 1994. The influences of tree biology and fire in the spatial structure of the West African savannah. Journal of Ecology 82:217226.

Homewood, K. M., and W. A. Rodgers. 1991. Maasailand ecology: pastoralist development and wildlife conservation in Ngorongoro, Tanzania. Cambridge University Press, Cambridge, UK.
Hudak, A. T. 1999. Rangeland mismanagement in South Africa: failure to apply ecological knowledge. Human Ecology 27:55-78.

Illius, A. W., and T. G. O'Connor. 1999. On the relevance of nonequilibrium concepts to arid and semiarid grazing systems. Ecological Applications 9:798-813.

Jackson, R. B., J. Canadell, J. R. Ehleringer, H. A. Mooney, E. O. Sala, and E. D. Schulze. 1996. A global analysis of root distributions for terrestrial biomes. Oecologia 108: 389-411.

Jeltsch, F., S. J. Milton, W. R. J. Dean, and N. Van Royen. 1996. Tree spacing and coexistence in semi-arid savannas. Journal of Ecology 84:583-595.

Jeltsch, F., S. J. Milton, W. R. J. Dean, N. Van Royen, and K. A. Moloney. 1998. Modelling the impact of small-scale heterogeneities on tree-grass co-existence in semi-arid savannas. Journal of Ecology 86:780-793.

Kaufmann, J. B., D. L. Cummings, and D. E. Ward. 1994. Relationships of fire, biomass and nutrient dynamics along a vegetation gradient in the Brazilian cerrado. Journal of Ecology 82:519-531.

Kelly, R. D., and B. H. Walker. 1976. The effects of different forms of land use on the ecology of a semi-arid region in south-eastern Rhodesia. Journal of Ecology 64:553-576.

Knoop, W. T., and B. H. Walker. 1985. Interactions of woody and herbaceous vegetation in a Southern African savanna. Journal of Ecology 73:235-253.

Lamprey, H. F., D. J. Herlocker, and C. R. Field. 1980. Report on the state of knowledge on browse in East Africa in 1980. Pages 33-54 in H. N. Le Houérou, editor. Browse in Africa: the current state of knowledge. International Livestock Centre for Africa, Addis Ababa, Ethiopia.

Le Houérou, H. N. 1980. Browse in Africa: the current state of knowledge. International Livestock Centre for Africa, Addis Ababa, Ethiopia.

Lockwood, J. A., and D. R. Lockwood. 1993. Catastrophe theory: a unified paradigm for rangeland ecosystem dynamics. Journal of Range Management 46:282-288.

Ludwig, D., B. Walker, and C. S. Holling. 1997. Sustainability, stability, and resilience. Conservation Ecology 1(1):7.[online, URL:〈http://www.consecol.org/voll1/iss1/ $\operatorname{art} 7\rangle$.]

McNaughton, S. J. 1985. Ecology of a grazing ecosystem: the Serengeti. Ecological Monographs 55:259-294.

Norton-Griffiths, M. 1979. The influence of grazing, browsing, and fire on the vegetation dynamics of the Serengeti. Pages 310-352 in A. R. E. Sinclair and M. Norton-Griffiths, editors. Serengeti: dynamics of an ecosystem. University of Chicago Press, Chicago, Illinois, USA.

Noy-Meir, I. 1975. Stability of grazing ecosystems: an application of predator-prey graphs. Journal of Ecology 63: 459-481.

Perrings, C., and B. Walker. 1997. Biodiversity, resilience and the control of ecological-economic systems: the case of fire-driven rangelands. Ecological Economics 22:73-83.

Pratt, D. J., and M. D. Gwynne. 1977. Range management and ecology in East Africa. Hodder and Stoughton, London, UK.

Prins, H. H. T., and H. P. Van der Jeugd. 1993. Herbivore population crashes and woodland structure in East Africa. Journal of Ecology 81:305-314.

Rietkerk, M., P. Ketner, L. Stroosnijder, and H. H. T. Prins. 1996. Sahelian rangeland development: a catastrophe? Journal of Range Management 49:512-519.

Rietkerk, M., and J. Van de Koppel. 1997. Alternate stable states and threshold effects in semi-arid grazing systems. Oikos 78:69-76.

Rietkerk, M., F. Van den Bosch, and J. Van de Koppel. 1997. Site-specific properties and irreversable vegetation changes in semi-arid grazing systems. Oikos 80:241-252. 
Sala, E. O., R. A. Golluscio, W. K. Lauenroth, and A. Soriano. 1989. Resource partitioning between shrubs and grasses in the Patagonian steppe. Oecologia 81:501-505.

Savage, M., and T. W. Swetnam. 1990. Early 19th-century fire decline following sheep pasturing in a Navajo ponderosa pine forest. Ecology 71:2374-2378.

Schenk, H. J., and R. B. Jackson. 2002. Rooting depths, lateral root spreads, and belowground/aboveground allometries of plants in water-limited ecosystems. Journal of Ecology 90:480-494.

Scholes, R. J., and S. R. Archer. 1997. Tree-grass interactions in savannas. Annual Review of Ecology and Systematics 28:517-544.

Scholes, R. J., and B. H. Walker. 1993. An African savanna: synthesis of the Nylsvley study. Cambridge University Press, Cambridge, UK.

Sinclair, A. R. E. 1979. Dynamics of the Serengeti ecosystem. Pages 1-30 in A. R. E. Sinclair and M. Norton-Griffiths, editors. Serengeti: dynamics of an ecosystem. University of Chicago Press, Chicago, Illinois, USA.

Smith, A. B. 1992. Pastoralism in Africa: origins and development ecology. Hurst, London, UK.

Stuart-Hill, G. C., and N. M. Tainton. 1989. Water utilisation patterns around isolated Acacia karoo trees in the false thornveld of the eastern Cape. Journal of the Grassland Society of South Africa 18:159-164.

Trollope, W. S. W. 1984. Fire in savanna. Pages 199-218 in P. D. V. Booysen and N. M. Tainton, editors. Ecological effects of fire of southern African ecosystems. SpringerVerlag, Berlin, Germany.

Trollope, W. S. W. 1996. Behaviour, effects and use of fire in the savannas of southern Africa. Pages 9-23 in T. C. Grice and S. M. Slatter, editors. Fire in the management of northern Australian pastoral lands. Proceedings of the Tropical Grassland Society of Australia 8.

Trollope, W. S. W. 1998. Effect and use of fire in the savanna areas of southern Africa. Department of Livestock and Pas- ture Science, Faculty of Agriculture, University of Fort Harare, Alice, South Africa.

Trollope, W. S. W., and L. A. Trollope. 1996. Fire in African savanna and other grazing ecosystems. Paper presented at the seminar on "Forest fire and global change" held in Shshenkoye in the Russian Federation, 4-10 August 1996.

Van de Vijver, C. A. D. M. 1999. Fire and life in Tarangire. Effects of burning and herbivory on an East African savanna system. Dissertation. Wageningen University, Wageningen, The Netherlands.

Van de Vijver, C. A. D. M., C. A. Foley, and H. Olff. 1999. Changes in the woody component of an East African savanna during 25 years. Journal of Tropical Ecology 15: 545-564.

Van Soest, P. J. 1982. Nutritional ecology of the ruminant. $\mathrm{O}$ and B Books, Corvallis, Oregon, USA.

Van Vegten, J. A. 1983. Thorn bush evasion in a savanna ecosystem in eastern Botswana. Vegetatio 56:3-7.

Van Wieren, S. E. 1992. Factors limiting food intake in ruminants and nonruminants in the temperate zone. Pages 139-145 in F. Spitz, G. Janeau, G. Gonzalez, and S. Aulagnier, editors. Ongulates/Ungulates 91. S. F. E. P. M.-I. R. G. M., Toulouse, France.

Walker, B. H. 1993. Rangeland ecology: understanding and managing change. Ambio 22:80-87.

Walker, B. H., D. Ludwig, C. S. Holling, and R. M. Peterman. 1981. Stability of semi-arid savannah grazing systems. Journal of Ecology 69:473-498.

Walker, B. H., and I. Noy-Meir. 1982. Aspects of the stability and resilience of savanna ecosystems. Pages 555-590 in B. J. Huntley and B. H. Walker, editors. Ecology of tropical savannas. Springer-Verlag, Berlin, Germany.

Walter, H. 1971. Ecology of tropical and subtropical vegetation. Oliver and Boyd, Edinburgh, UK.

Weltzin, J. F., and G. R. McPherson. 1997. Spatial and temporal soil moisture resource partitioning by trees and grasses in a temperate savanna, Arizona, USA. Oecologia 112: 156-164.

\section{APPENDIX}

Formal stability analyses of the tree-grass model $d W / d t$ and $d H / d t$ given by Eqs. 3 and 7 are available in ESA's Electronic Data Archive: Ecological Archives E084-008-A1. 